\title{
Vestibulo-spinal response modification as determined with the H-reflex during the Spacelab-1 flight
}

\author{
M.F. Reschke ${ }^{1}$, D.J. Anderson ${ }^{2}$, and J.L. Homick ${ }^{1}$ \\ ${ }^{1}$ Space Biomedical Research Institute (SB), Johnson Space Center, Houston, TX 77058, USA \\ ${ }^{2}$ Kresge Hearing Research Institute, University of Michigan, Ann Arbor, MI 48109, USA
}

Summary. Our laboratory at the Johnson Space Center has employed the H-reflex recorded from the soleus muscle as a method of monosynaptic reflex testing in conjunction with vertical linear accelerittion to assess modification of utriculo-saccular function induced through prolonged exposure to microgravity. It was hypothesized that exposure to free fall would reduce the necessity for postural reflexes in the major leg muscles, and that postural modification would reflect a change, not in the peripheral vestibular organs, but more centrally. This postural adjustment would reflect a sensory motor rearrangement where otolith receptor input was reinterpreted to provide an environmentally appropriate response. In addition to the H-reflex (which was the only inflight measurement), vestibulo-spinal EMG from the gastrocnemius, and self-motion reports were obtained in response to a sudden earth vertical fall. Preflight, inflight and postflight motion sickness reports were also recorded, and related to the H-reflex data. The results indicated that early inflight H-reflex amplitude was similar to that recorded preflight, but that measurements obtained later in the flight (day seven) did not show a change in potentiation as a function of the different drop to shock intervals. Immediate postflight H-reflex response in three of the four astronauts tested showed a rebound effect. Postflight gastrocnemius EMG in response to the sudden fall did not show a significant change from preflight values. However, one crewman who was tested early postflight did show an increase in EMG activity in response to the sudden fall. This immediate postflight effect returned to baseline rapidly. Self-motion perception obtained inflight suggested that the early inflight drops were perceived like those preflight. Drops later inflight were described as sudden, fast, hard and transla-

Offprint requests to: M.F. Reschke (address see above) tional in nature. Immediately postflight the drops were perceived like those late inflight, and the astronauts said that they did not feel as though they were falling, rather the floor came up to meet them. Post hoc peak H-reflex amplitude, both preflight and postflight was related to inflight space motion sickness.

Key words: H-reflex - Earth vertical fall - Utriculosaccular - Vestibular - EMG - Space motion sickness - Vestibulo-spinal - Space flight - Spacelab-1

\section{Introduction}

Two of the most dramatic changes related to orbital flight have been postural disturbances (Homick and Reschke 1977) and modified reflex activity in the major weight-bearing postural muscles (Baker et al. 1977; Vorokyov et al. 1982; Clement et al. 1985). Recently it has been suggested that these changes are due to sensory rearrangement and may represent a reinterpretation of vestibular, visual and proprioceptive input (Lackner 1978; Reschke et al. 1984a; Young et al. 1984; Parker et al. 1983, 1984, 1985). The reinterpretation of otolith signals is of primary interest to this investigation, and may be revealed during flight and immediately postflight by changes in postural responses, eye movement reflexes and self-motion perception.

Taking advantage of the powerful and established anatomical pathways that link the otolith receptors and spinal motoneurons, our laboratory at the Johnson Space Center (Reschke et al. 1985a) has employed the H-reflex (Hoffmann 1918, 1922; Magladery 1955) recorded from the soleus muscle as a method of monosynaptic reflex testing in conjunction with vertical linear acceleration to assess modifica- 

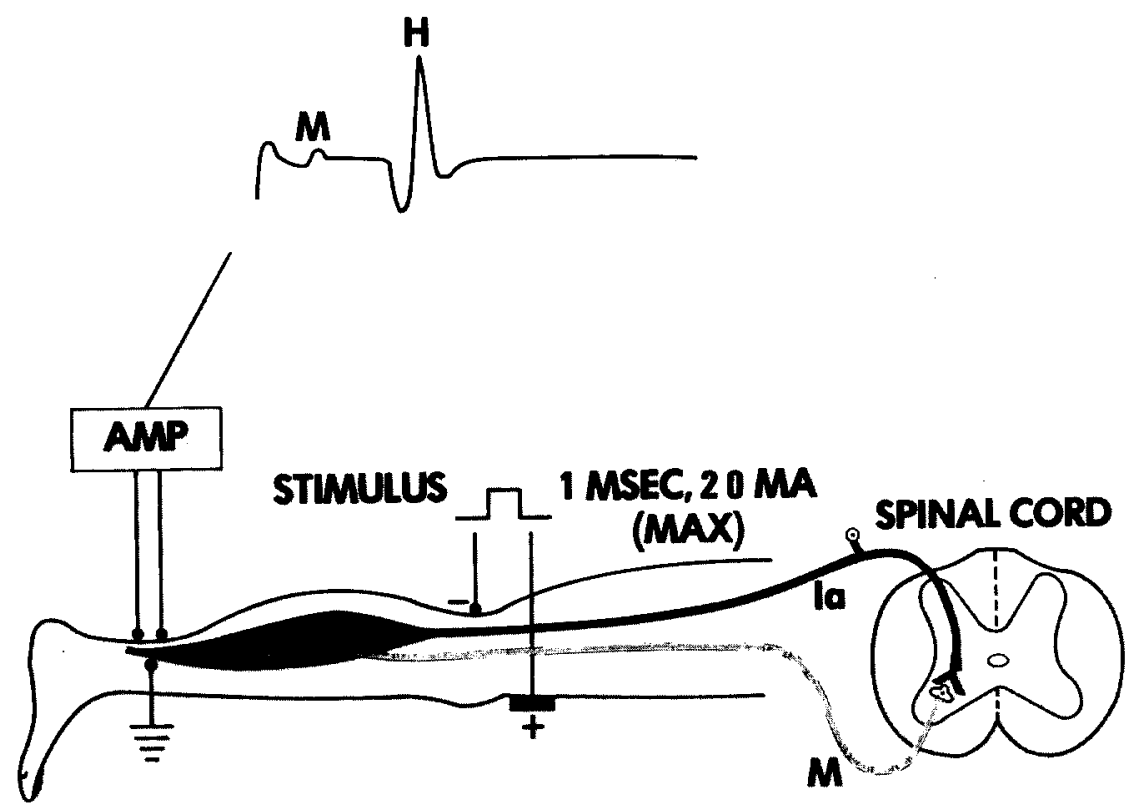

Fig. 1. H-reflex pathway, stimulation and recording methods as applied to astronaut subjects. A brief 1 ms constant current pulse, limited to 20 ma maximum was applied to the needle cathode electrode inserted into the popliteal fossa at a predetermined and tattooed location. A needle was selected as the active stimulating electrode to avoid movement artifact during the sudden fall. Sterile techniques were used for insertion of the needle, including the application of betadine. The anode was a $13.5 \mathrm{~cm}^{2}$ plate secured above the patella with rubber straps and surgical tape. Care was taken to prevent ischemia when the anode was applied. The recording electrodes were placed at predetermined and tattooed locations near the insertion of the soleus into the tendon. Prior to their application the skin surface was cleaned with alcohol, and a $1 \mathrm{~mm}$ long scratch was placed in the skin to lower electrode impedance. Impedance was verified and electrodes replaced if it was above $5 \mathrm{~K}$ ohms. All recording was bipolar. The single body ground was placed lateral to the recording electrodes forming an equilateral triangle. Prior to collection of the recruitment curves or data from a sudden fall, the placement of the electrodes and dynamic range of the muscle response was verified

tion of utriculo-saccular function induced through prolonged exposure to microgravity.

The procedures for eliciting the H-reflex in man have been well documented by Hugon (1973). Using this method Watt (1976) investigated in decerebrate cats the effects of vertical acceleration on motoneuron pool excitability in the lumbosacral spinal cord. A significant reflex effect requiring an acceleration of $0.1 \mathrm{~g}$ or more, acting on the otolith apparatus for the postural mechanisms was observed.

Matthews and Whiteside (1960) dropped human subjects in a seated position to investigate both stretch reflexes and the H-reflex as a function of zero-g. Their results indicated a decrease in amplitude of the $\mathrm{H}$-reflex which occurred from 50 to $100 \mathrm{~ms}$ after the subject was dropped. These results are not consistent with observations by Melvill Jones and Watt (1971) of a short latency $(75 \mathrm{~ms})$ EMG response recorded from the gastrocnemius in man to the sudden unexpected short fall, or with the experiments of Greenwood and Hopkins (1974, 1976a, 1976b) who found that in longer falls $(>200 \mathrm{~ms})$ the initial short latency EMG burst was followed by a second peak of activity timed to occur before the moment of landing. It seems unlikely that the $\mathrm{H}$ reflex would be attenuated in the same time frame as increased muscle activity in the soleus and gastrocnemius is present.

These earlier observations of Greenwood and Hopkins (1974, 1976a, 1976b) were later supported with a study (Greenwood and Hopkins 1977) which exposed subjects to an unexpected drop while they were either seated or hanging in a parachute harness. Unlike Matthews and Whiteside they found an overall facilitation $(200-500 \%)$ over control in the soleus H-reflex which began approximately 30 to $40 \mathrm{~ms}$ after release.

More recently, Watt (1981) investigated the effect of labyrinthectomy on the H-reflex in cats subjected to a sudden fall. Normal cats demonstrated an early suppression of the H-reflex (unlike the facilitation measured by Greenwood and Hopkins 1977). This early suppression was effectively abolished in the labyrinthectomized animals.

Research in our laboratory (Reschke et al. 1976; Reschke et al. 1979; Reschke et al. 1985a) supports the findings of those investigators who show a potentiation of the H-reflex response as a function of 


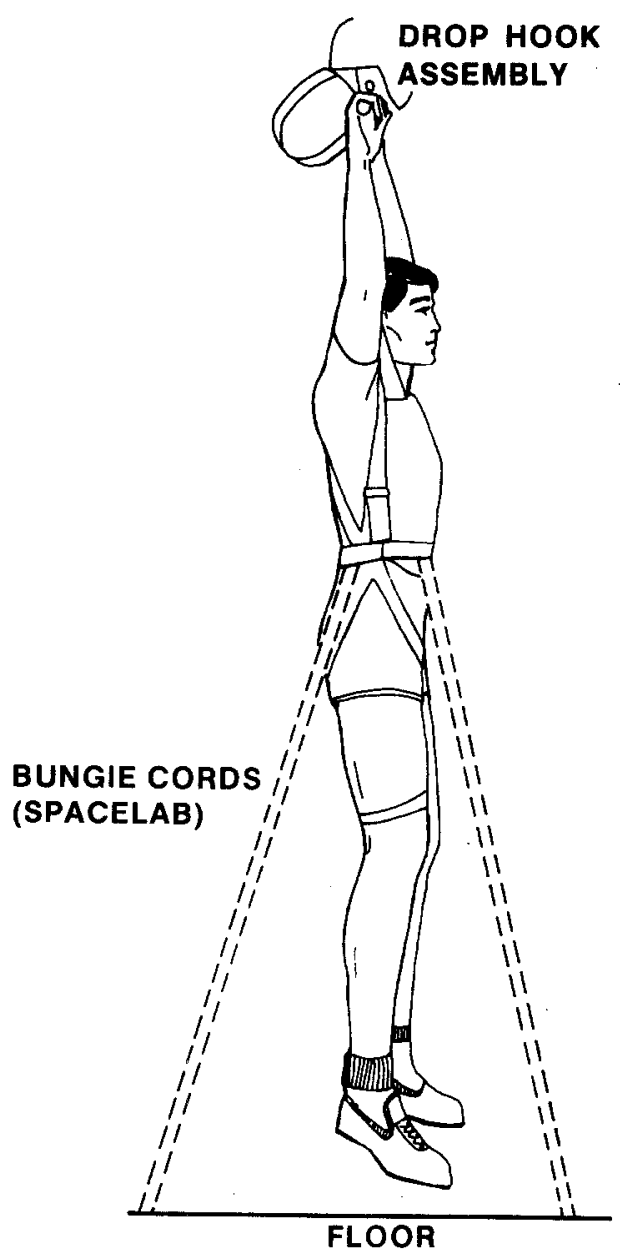

Fig. 2. The drop hook assembly for ground testing was a quick release helicopter cargo hook. Inflight the drop assembly was provided by Watt (Young et al. 1984). The handle on which the subject was hung from the assembly was attached to a quick release lever under computer control. The subject was connected to the handle with straps from a shoulder harness. These straps and harness relieved the subject from bearing his own weight. Hands were only placed on the drop handle for stability. The dashed lines indicate the calibrated bungie cords used to pull the subject to the Spacelab deck

free fall and reduced gravity loads. Using human subjects we have employed soleus/spinal H-reflex testing procedures in conjunction with an accelerative stimulus of approximately $1.8 \mathrm{~g}$ through $1 \mathrm{~g}$ to free fall (provided by NASA's KC-135 parabolic airplane) to assess changes in the vestibulo-spinal motoneuron pool as a function of variable background acceleration on the otoliths.

Based on the results of these studies where the $\mathrm{H}$ reflex was modulated as a function of gravity, it was hypothesized that exposure to free fall for a prolonged period of time would reduce the necessity for postural reflexes in the major postural muscles, and that postural modification would reflect a change, not in the peripheral vestibular organs (otolith), but more centrally. This postural adjustment would reflect a sensory motor rearrangement where otolith receptor input was reinterpreted to provide an environmentally appropriate response. Based on this hypothesis, the purpose of this experiment was to: 1 ) Investigate vestibulo-spinal responses as a function of prolonged space flight, 2) employ the H-reflex as a means of determining the excitability of the lumbar/ sacral motoneuron pool, 3) investigate the concept that vestibular adaptation (utriculo-saccular in particular) is central rather than peripheral, and 4) relate space motion sickness susceptibility to the results of the vestibulo-spinal responses.

\section{Methods}

Four of the six crewmembers assigned to the Spacelab-1 mission served preflight and postflight as subjects for this investigation. Inflight two of these crewmen participated in data collection. Preflight data were obtained 151,121, 65, 44 and 10 days prior to the flight (F-151, F-121 . . , etc.), on day 2 and day 7 of the 9 day flight (Mission Elapsed Time-01 and MET-06) and postflight on the day of landing $(R+0)$, and then on $R+1, R+2, R+4$ and $\mathrm{R}+6$. A later data point was collected on one of the crew at $\mathrm{R}+120$.

\section{Hoffman reflex}

The monosynaptic reflex as shown in Fig. 1 was activated by electrical stimulation of the large group Ia fibers in the popliteal nerve and recorded from the soleus muscle. A modified $26 \mathrm{~g}$ hypodermic needle served as the cathode, and was inserted in the popliteal fossa at a predetermined and permanently marked (tattoo) location on the right leg. The anode, a $5 \times 2.7 \mathrm{~cm}$ stainless steel plate electrode, was secured just above the patella after cleaning the area with alcohol and applying Grass electrode paste. Different levels of $1 \mathrm{~ms}$ constant current pulses limited to a maximum of $20 \mathrm{ma}$ were delivered through an isolation unit under computer control. A differential amplifier and bipolar electrode configuration was used to record the reflex from the soleus muscle. The muscle response was band pass filtered by the amplifier between 50 and $350 \mathrm{~Hz}$, digitized on line at $2000 \mathrm{samples} / \mathrm{s}$ for ground operations and at $2560 \mathrm{samples} / \mathrm{s}$ inflight. The recording electrodes (AMED disposable infant) were placed on the right leg at predetermined and tattooed positions along the mid-dorsal axis over the soleus muscle just below the junction of the Achilles tendon and the two heads of the gastrocnemius. Prior to application of the electrodes, the site was cleansed with alcohol and the bevel edge of a 19 gage hypodermic needle was used to place a $1 \mathrm{~mm}$ long scratch in the skin. Electrode impedance was checked and if it was greater than $5 \mathrm{~K} \Omega$ the electrodes were replaced following a second skin scratch. The response to stimulation had two components: a direct orthodromic muscle response (M-wave) with a latency of 5 to $10 \mathrm{~ms}$ that was followed 15 to $20 \mathrm{~ms}$ later by the monosynaptic H-reflex. Because the M-wave represented a direct muscle response and is not modified by spinal components or descending signals, it was used as the drop control response to assure constant effective stimulation. The H-reflex amplitude, assuming little presynaptic control, reflected the sensitivity of the lumbosacral motoneuron pool as set by the descending postural control signals. 


\section{Vestibular stimulation}

Vestibular (utriculo-saccular) stimulation during preflight and postflight testing (Fig. 2) was provided by unexpectedly dropping the subject in a special harness designed to leave the arms and legs free and unloaded, using a quick-release helicopter cargo hook. The subject's harness was suspended from a $\mathrm{T}$-shaped handle. The handle was engaged in the quick release mechanism by requiring the subject to stand on a stool approximately $15 \mathrm{~cm}$ in height. Once the subject was supported by the drop mechanism, the stool was removed to leave the subject hanging free. For each drop the subjects were shocked three times. The first shock, used to condition the neural tissue, was followed three seconds later by a shock that elicited a control response, and the third, 3 to $5 \mathrm{~s}$ later, was delivered at predetermined time delays from the onset of the drop. Shocks during the fall occurred coincident with the drop ( $0 \mathrm{~ms}$ delay) or at $10 \mathrm{~ms}$ intervals up to $80 \mathrm{~ms}$ following initiation of the drop. An experimental session was comprised of four drops at nine randomized delay times for a total of thirty-six drops. The averaged response to the test shock was normalized with respect to the averaged control shocks and presented as a percent change in $\mathrm{H}$-wave (or $\mathrm{M}$-wave) amplitude. To insure that the afferent volley which produced the H-reflex did not excite $100 \%$ of the motoneuron pool and occlude the effect from the sudden fall, two methods were used. First, recruitment curves for the M- and Hwaves were determined prior to each series of drops. These curves were generated by shocks at threshold level used to produce a just detectable H-reflex, and then the current was increased in discreet steps until a maximal H-reflex was obtained. Further increases in current were then used to produce a maximal M-wave and block the H-response through antidromic collision. Eight responses were summed at each discreet current step. Second, with the subject in the hanging position, amplitude of the $\mathrm{H}$-reflex was set at $50 \%$ of maximum amplitude. This procedure was employed because the amplitude of the $\mathrm{H}$-reflex frequently changed from the standing recruitment curve to the hanging position. The $50 \%$ amplitude of the H-reflex was verified following every fourth drop, and a drop was aborted if the control $\mathrm{H}$-reflex amplitude was lower or higher than $50 \%$ of the maximum established in the hanging position. A dedicated microcomputer (LSI-11) was used on-line to control the experiment. Four programs were supplied with the computer. These included: (1) control of the drop mechanism; (2) H-reflex stimulus sequence/delay; (3) data collection, storage and analysis; and (4) graphics.

Inflight, we used the Canadian "hop and drop" station (Young et al. 1984), a special harness arrangement to unload the subject's arms and legs, drop apparatus and calibrated bungie cords (Fig. 2) adjusted to pull the subject to the floor of the Spacelab with a transition from free fall to $-1 \mathrm{~g}$. A stool velcroed to the deck of the Spacelab allowed the subject to engage the Thandle in the drop mechanism. The drop to shock delay times employed inflight ranged from 0 to $70 \mathrm{~ms}$ in $10 \mathrm{~ms}$ increments. On MET-01 four responses at each of the eight delays were recorded. On MET-06 only two responses at each of the delay times were obtained. Recruitment curves were obtained prior to each session with the subject standing and restrained with the bungie cords. The inflight computer (a modified PDP-8e) was used to control the experiment, release the drop mechanism, time the electric shock and collect the data. The data was either "dumped" real time to the ground, or stored on digital tape until it could be dumped.

Preflight and postflight skull acceleration was obtained, with a DC linear $\mathrm{Z}$ axis accelerometer attached to a bite board and held in the subject's mouth during the drop. Inflight (Young et al. 1984), the accelerometer was attached to the back of the head with a velcro strap arrangement. The signal from the accelerometers was digitized at approximately 100 samples/s. Actual release times for the drops were determined by comparing the computer voltage command to drop with the accelerometer output. There was a $20 \mathrm{~ms}$ delay in both the ground and flight drop systems meaning that the subjects were dropped $20 \mathrm{~ms}$ prior to the command to initiate data collection and recording. Landing times on the ground were obtained using ribbon switches placed under a rubber mat. Inflight contact with the deck of the Spacelab was detected with a foot shaped set of ribbon switches attached to the subject's right foot. Both the inflight and ground drops were obtained with the subject's eyes open, primarily for safety reasons.

\section{Gastrocnemius EMG responses}

To investigate the relationship of the direct vestibulo-spinal reflex to the $\mathrm{H}$-reflex response, EMG activity as a function of the sudden drop, recorded from the gastrocnemius muscles of the subject's left leg, was amplified, band pass filtered between $1 \mathrm{~Hz}$ and $1 \mathrm{kHz}$ and digitized in real time at 1000 samples/s. The RMS amplitude of the EMG activity was then determined over a $100 \mathrm{~ms}$ sweep that was windowed between 50 and $150 \mathrm{~ms}$ of the total time of the sudden fall. The infant (AMED) disposable electrodes used to record EMG activity were placed on the belly of the gastrocnemius muscle over tattoo marks. The location of these tattoo marks were determined, and placed by Watt to obtain similar data with the Spacelab-1 crew (Young et al. 1984). Method of application was the same as that used for the electrodes employed to record the $\mathrm{H}$ reflex. Prior to each set of drops, the EMG was calibrated with an external signal applied through the electrode cable leads.

\section{Space motion sickness and self-motion reports}

Both the degree and severity of space motion sickness experienced by the four crewmembers was monitored by this experiment and as part of another experiment (Young et al. 1984; Oman et al. 1984). This was done with interviews and a questionnaire which were calibrated by the crewmen's preflight response to terrestrial provocative motion sickness testing. A ranking procedure was applied to the flight motion sickness responses, and the ranked order related to the peak H-reflex drop to shock preflight average for each crewman and with the postflight H-reflex curves.

Self-motion responses were obtained preflight, inflight and postflight. The crewmen were asked to describe the sensation experienced during the sudden falls and to note any unusual effects or illusions. In particular, they were to report duration, out of plane motion and translational sensations.

\section{Results}

\section{Motoneuron pool excitability}

Figure 3 shows a typical set of responses to a brief unexpected fall from $1 \mathrm{~g}$ to free fall (a step acceleration of $9.8 \mathrm{~m} / \mathrm{s}^{2}$ ). The response in the box at the top of the figure is the control H-reflex response that was obtained approximately 3 to $5 \mathrm{~s}$ prior to the actual drop. The top trace shows the test H-reflex in response to the drop. In this case the test shock was delivered at a drop to shock delay of $70 \mathrm{~ms}$. Note the large potentiation of the H-reflex, with no change apparent in the $\mathrm{M}$-wave response, as a function of the drop. The second trace represents the EMG data 


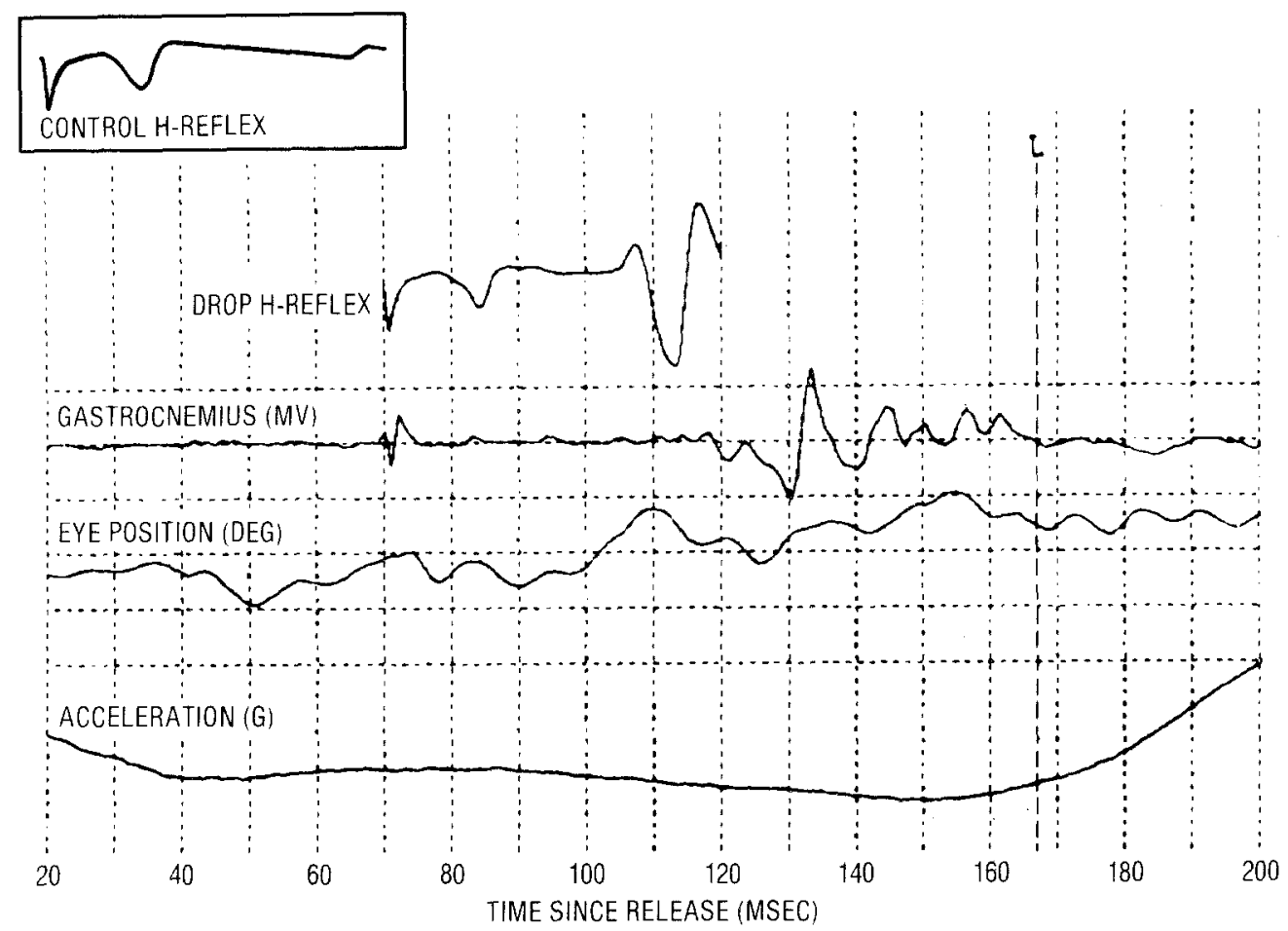

I $580 \mathrm{MV}$ I $34 \mathrm{DEG}$ I $0.6 \mathrm{G}$

Fig. 3. Analog parameters recorded from subject B 10 days prior to flight. All data was collected and digitized on-line in real time. The control response is located in a box. The amplitude of the M-wave was $2168 \mathrm{mv}$ and that of the H-reflex was $544 \mathrm{mv}$. Below the control response is the $\mathrm{M}$ and $\mathrm{H}$-reflex test response, elicited at a drop to shock interval of $70 \mathrm{~ms}$. EMG from the gastrocnemius, eye position and skull acceleration. Note calibration values

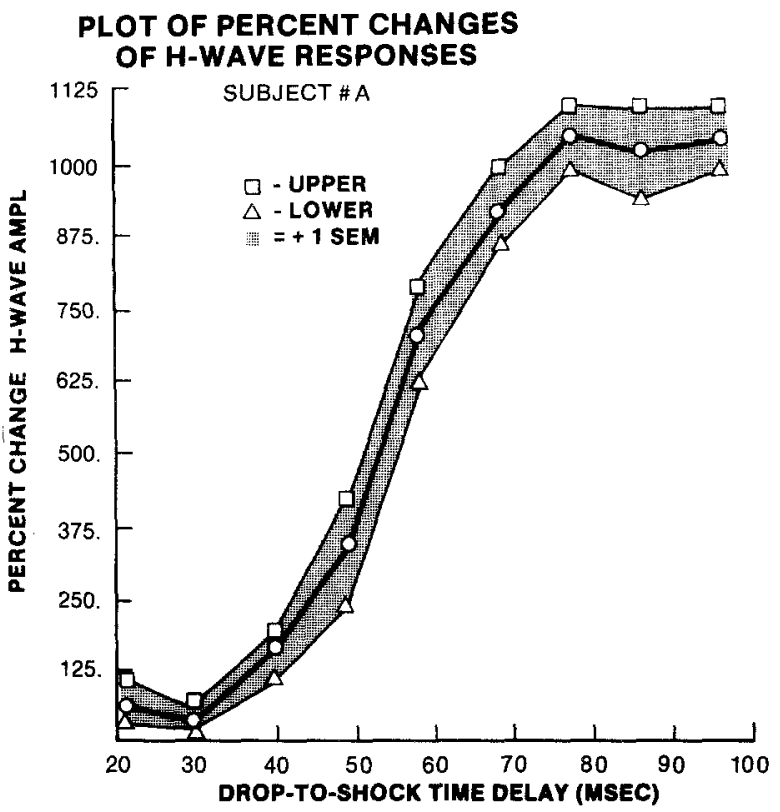

Fig. 4. Drop to shock potentiation of the average preflight $H$ reflex response obtained for subject $B$. Potentiation begins at a drop to shock interval of approximately 30 or $40 \mathrm{~ms}$. The response variance, presented as \pm 1 SEM in this figure was representative of the four subjects tested obtained from the gastrocnemius muscles of the right leg. The third trace is the vertical position of the eye in response to the drop. The fourth trace from the top represents $\mathrm{Z}$ axis acceleration (the sharp transition in acceleration is not observable in this trace because of the $20 \mathrm{~ms}$ delay in data acquisition from the time of the actual drop). Landing time relative to the release of the subject is indicated by the vertical dashed line at $167 \mathrm{~ms}$.

Figure 4 is a typical drop to shock response curve showing the potentiation of the H-reflex as a function of drop to shock delay time. The variability $( \pm 1$ SEM) indicated on this graph is representative of the typical variance associated with data collected with this method. Each data point that represents a drop to shock delay time is the average response of $20 \mathrm{H}$ reflex responses obtained over five preflight test days from one subject with four responses recorded at each drop to shock delay for each test session. Note that potentiation of the H-reflex begins between 30 and $40 \mathrm{~ms}$ and reaches a maximum peak value at $80 \mathrm{~ms}$. The percent change on the $\mathrm{Y}$ axis represents a difference percentage where the test $\mathrm{H}$-reflex response is the difference from the average control re- 


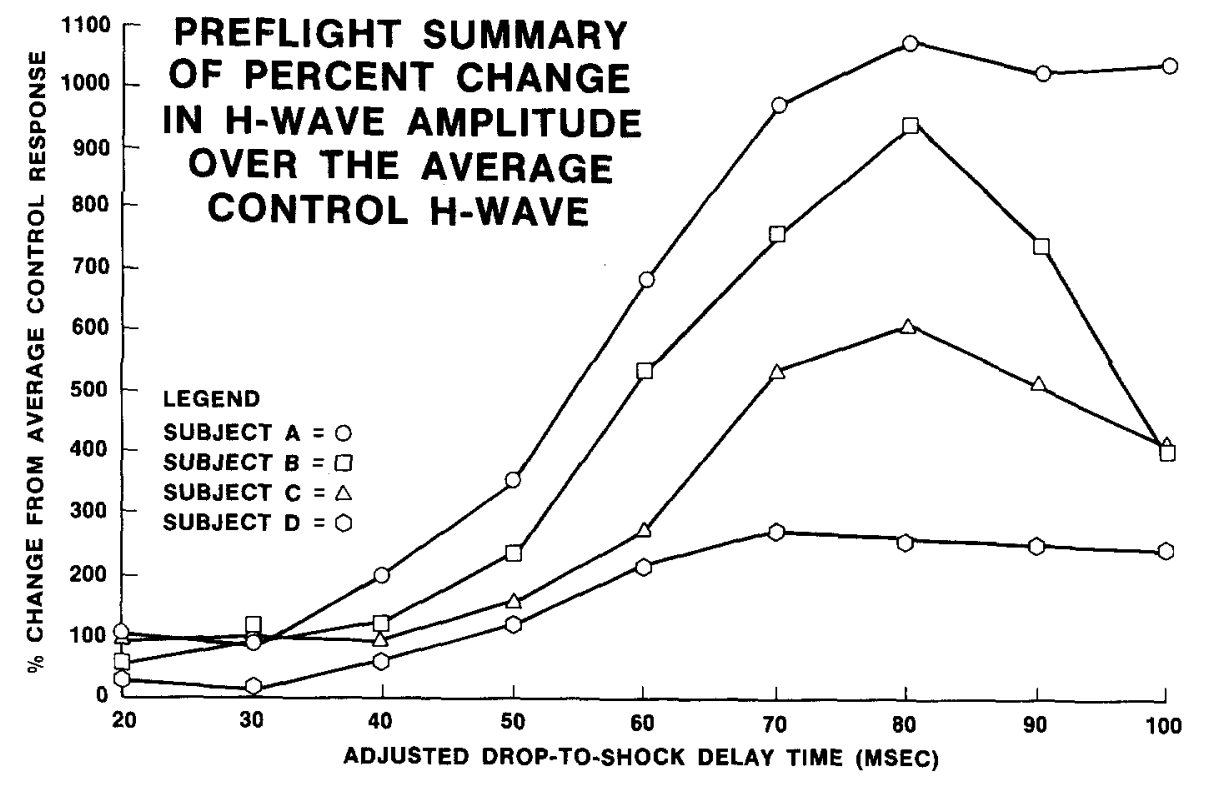

Fig. 5. Comparison of the average preflight drop to shock H-reflex potentiation of the four astronauts. Note that there is considerable difference in motoneuron pool excitability between each of the crewmen tested. The downward trend beginning at $80 \mathrm{~ms}$ for subjects $\mathrm{B}$ and $\mathrm{C}$ may have been due to their height (a longer H-reflex loop)

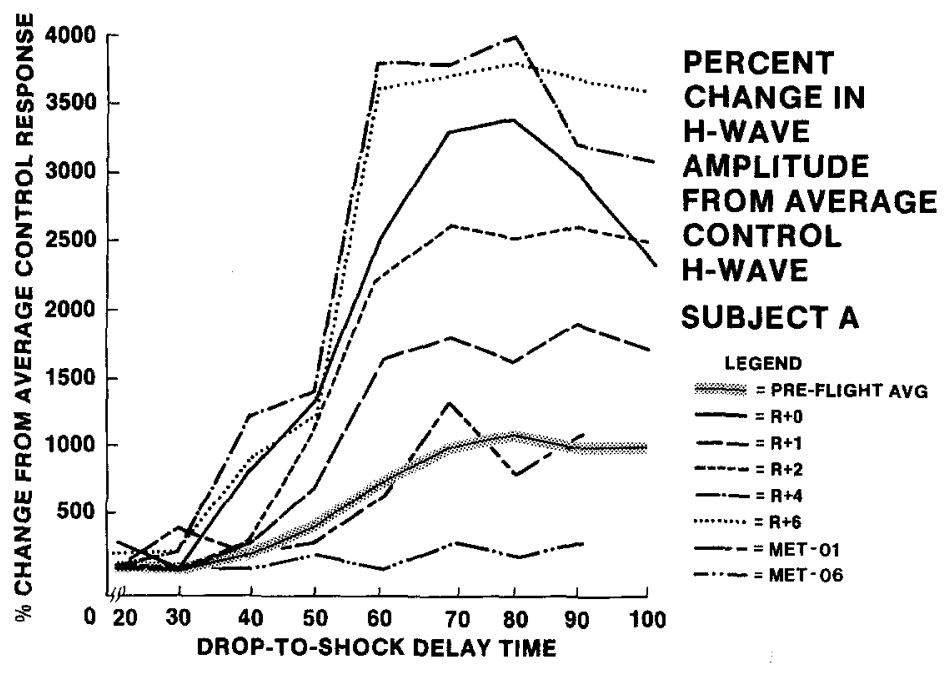

Fig. 6. Drop to shock H-reflex potentiation summary representing the response changes recorded from subject A preflight baseline. Immediately postflight the $\mathrm{H}$ reflex is potentiated approximately 3 -fold. By $\mathrm{R}+1$ potentiation shows a trend to return to baseline. However, on $\mathrm{R}+2$ the potentiation shows a rebound that continues and increases beyond response amplitude obtained on $R+0$. Subject $A$ was last tested seven days $(R+6)$ following the flight. At that time he had not returned to baseline. Inflight testing show that the $24 \mathrm{~h}$ (MET-01) H-reflex drop to shock potentiation was similar to that obtained preflight. By MET-06 the $\mathrm{H}$-reflex shows little or no potentiation as a function of the drop to shock interval

sponse. That is, percent change from average control response is:

$$
=\frac{\mathrm{HT}-\overline{\mathrm{HC}}}{\overline{\mathrm{HC}}} \times 100
$$

where $\mathrm{HT}$ is the test $\mathrm{H}$-reflex amplitude, and $\overline{\mathrm{HC}}$ is the average H-reflex amplitude of all control drops from an experimental session.

Figure 5 represents a preflight summary of the four crewmen tested. Again each drop to shock delay point represents an average of $20 \mathrm{H}$-reflex responses for each of the four subjects. This family of curves shows that there were considerable preflight differences in the motoneuron pool excitability between the crewmen tested. The maximum response from subject D was less than $300 \%$ change in H-reflex amplitude over control values, while that for subject A was as high as $1100 \%$. A two way analysis of variance (Winer 1971; Lin 1983) with the drop to shock delay time as a repeated measure and subject as a grouping factor was used to test for overall differences in the data presented in Fig. 5. In this test a Dunnett (1964) unadjusted p-value was used with the subject factor and adjusted p-values (Greenhouse and Geisser 1959) were used with the repeated factors (drop to shock delay time and subject by drop to shock delay time). Results of the analysis indicated that differences in the means for the subject and the drop to shock delay time factors were significantly different $(p<0.001)$. This analysis only indicates significant differences across subjects, but not between subjects. The results of a Dunnett a posteri- 
Table 1. Results of the Dunnett tests. Percent changes of H-reflex peak to peak responses as a function of the control responses (each individual inflight and postflight test days versus the preflight average)

\begin{tabular}{|c|c|c|c|c|c|c|}
\hline Subject & $\begin{array}{l}\text { Preflight } \\
\text { inflight and } \\
\text { postflight } \\
\text { test day }\end{array}$ & $\mathrm{N}$ & Mean and S.E.M. & $\begin{array}{l}\text { Diff from } \\
\text { preflight } \\
\text { average }\end{array}$ & Diff/S & $\begin{array}{l}\text { Critical value } \\
\text { from Dunnett } \\
\text { table }\end{array}$ \\
\hline & Preflight & 180 & $(34.5)$ & - & - & - \\
\hline & $R+0$ & 36 & $1925,7 \quad(255.9)$ & 1308 & $13.7^{\mathrm{a}}$ & 3.15 \\
\hline & $\mathbf{R}+1$ & 36 & $1080.0 \quad(130.0)$ & 462 & $4.8^{\mathrm{a}}$ & 3.15 \\
\hline Subject & $R+2$ & 36 & $1568.3 \quad(192.2)$ & 950 & $9.9^{\mathrm{a}}$ & 3.15 \\
\hline \multirow[t]{7}{*}{ A } & $R+4$ & 36 & $2311.0 \quad(259.8)$ & 1693 & $17.7^{\mathrm{a}}$ & 3.15 \\
\hline & $R+6$ & 36 & $2321.7 \quad(269.6)$ & 1703 & $17.8^{\mathrm{a}}$ & 3.15 \\
\hline & MET-01 & 19 & $648.3(127.0)$ & 30 & 0.32 & 3.15 \\
\hline & MET-06 & 14 & $185.5(34.2)$ & 432 & $-7.6^{\mathrm{a}}$ & 3.15 \\
\hline & Preflight & 180 & $439.0 \quad(25.9)$ & - & - & - \\
\hline & $\mathbf{R}+0$ & 36 & $928.5 \quad(134.6)$ & 489 & $11.5^{\mathrm{a}}$ & 3.11 \\
\hline & $\mathbf{R}+1$ & 36 & $866.8 \quad(125.7)$ & 428 & $10.1^{\mathrm{a}}$ & 3.11 \\
\hline Subject & $\mathrm{R}+2$ & 36 & $1070.2 \quad(156.9)$ & 631 & $14.9^{\mathrm{a}}$ & 3.11 \\
\hline \multirow[t]{5}{*}{ B } & $R+4$ & 36 & $953.3 \quad(147.4)$ & 514 & $12.1^{\mathrm{a}}$ & 3.11 \\
\hline & $R+6$ & 36 & $730.0 \quad(95.1)$ & 291 & $6.9^{\mathrm{a}}$ & 3.11 \\
\hline & MET-06 & 13 & $117.7 \quad(28.5)$ & -321 & $-7.6^{\mathrm{a}}$ & 3.11 \\
\hline & Preflight & 180 & $163.7(8.8)$ & - & - & - \\
\hline & $\mathbf{R}+\mathbf{1}$ & 36 & $166.3(17.0)$ & 2.6 & 0.3 & 3.00 \\
\hline Subject & $R+2$ & 36 & $233.2(25.5)$ & 69.6 & $7.9^{\mathrm{a}}$ & 3.00 \\
\hline \multirow[t]{2}{*}{$\mathrm{D}$} & $\mathbf{R}+4$ & 36 & $153.3(13.3)$ & -10.6 & -1.2 & 3.00 \\
\hline & $R+6$ & 36 & $182.7 \quad(18.7)$ & 18.6 & -2.1 & 3.00 \\
\hline
\end{tabular}

${ }^{a}$ Indicates significance at the 0.01 level. $\mathrm{S}=2 \mathrm{MS}$ error $/ \mathrm{n}=95.75$ for subject $\mathrm{A}, 42.47$ for subject $\mathrm{B}, 8.70$ for subject $\mathrm{D}$

ori multiple comparison test (Dunnett 1964; Winer 1971) did however indicate that the means for each subject's drop to shock delay time did differ significantly from each other $(p<0.01)$. This difference in magnitude was related to inflight space motion sickness susceptibility (see below) as experienced by the individual crewmembers.

\section{Preflight, inflight and postflight $H$-reflex summary}

Figure 6 shows preflight, inflight and postflight response curves for subject $\mathrm{A}$. This is a complete family of curves with two inflight measurements which indicates that the percent change of the $\mathrm{H}$ reflex obtained after approximately $24 \mathrm{~h}$ on orbit was similar to the preflight response. By the seventh day inflight (MET-06) it was clear that a dramatic change had occurred. The H-reflex no longer showed potentiation as a function of the drop to shock delays as it did preflight or early inflight. In contrast, the $\mathrm{R}+0$ data (approximately $2.5 \mathrm{~h}$ after landing) showed a large, three-fold, potentiation of the H-reflex over preflight averages. By $\mathrm{R}+1$ there was a response decrease indicating a tendency for return to baseline. However, the data for $\mathrm{R}+2$ showed a rebound with a maximum percent change above $\mathrm{R}+1$ and $\mathrm{R}+0$. This rebound continued on $\mathrm{R}+4$ and $\mathrm{R}+6$ with approximately a four-fold increase in the percent change over the preflight maximum. It is possible that the rebound was caused by an intervening parabolic flight used as part of the postflight test procedures for another group of experiments (Young et al. 1984). No additional data were collected for subject A following the $R+6$ test. A return to baseline values is assumed based on the data obtained from subject $B$ (see below).

The results of the global F-test (Winer 1971) on the percent change of $\mathrm{H}$-wave peak responses for subject A compared with the peak control responses showed a significant difference $(p<0.01)$ for test day, drop to shock delay time and test day by delay time. The Dunnett (Dunnett 1964; Winer 1971) a posteriori multiple comparison tests on the data for subject A (see Table 1) showed that the means of the percent change of the $\mathrm{H}$-reflex responses of all inflight and postflight test days, except MET-01 were significantly different $(p<0.01)$ from that of the preflight test days.

No inflight data was obtained from subject $B$ on MET-02 due to space motion sickness problems. However, the percent change in the H-reflex response on MET-06 was equivalent to that obtained from subject $\mathrm{A}$. That is, the H-reflex showed little or 
no potentiation as a function of the drop to shock delay. Postflight, on $\mathrm{R}+0$ there was a large increase in peak H-reflex responses from a preflight average of $900 \%$ to approximately $1900 \%$. On $\mathrm{R}+1$ the maximum percent change had dropped below the $\mathrm{R}+0$ value to $1700 \%$. As with subject $\mathrm{A}$, there was a rebound on $\mathrm{R}+2$ and $\mathrm{R}+4$ which resulted in peak percent changes near those obtained for $R+0$. By $R+6$, subject $B$ was showing a tendency to return to baseline values with a maximum drop to shock percent change of approximately $1300 \%$ over the average control response for that day. Subject B was again tested on $\mathrm{R}+120$, and showed responses somewhat lower than the preflight values. Because of the long interval between $R+6$ and $R+120$ it cannot be determined when the return to baseline actually occurred. An overall F-test (Winer 1971) showed that there was a significant difference $(p<0.01)$ for percent changes of $\mathrm{H}$-reflex peak responses when compared to the control responses for test day, drop to shock delay time and test day by delay time. The Dunnett (Dunnett 1964; Winer 1971) posteriori multiple comparison tests (see Table 1) showed that the means of the percent changes of the five preflight test days combined, and of the inflight and postflight test days were significantly different $(p<0.01)$. The data obtained from subject $B$ on $R+120$ were not subject to this analysis, but due to the similarity with the preflight average it is reasonable to assume that this test day was not significantly different.

As indicated above, subjects $C$ and $D$ were not tested inflight, or postflight on $\mathrm{R}+0$. For the days that they were tested, the H-reflex amplitude for subject $\mathrm{C}$ showed a potentiation of approximately $800 \%$ over control values for $\mathrm{R}+1$ and $\mathrm{R}+2$. This is an increase of about 200 to $300 \%$ above the preflight value. $B y \quad R+4$ subject $C$ had returned to baseline. Even with the slight response potentiation postflight the overall F-test (Winer 1971) for subject C did not show a significant difference in percent change of the $\mathrm{H}$-reflex responses as a function of test day or test day by drop to shock delay time. For this reason data from subject $C$ was not subjected to the Dunnett (Dunnett 1964; Winer 1971) a posteriori multiple comparison test.

The data for subject $D$ indicated a preflight peak percent change from control values of approximately $260 \%$. There was little change postflight on $\mathrm{R}+1$ from the preflight response. On $\mathrm{R}+2$ there was a slight rebound (peak H-reflex response of 400\%) which was statistically significant (see Table 1), but constituted a minor change when compared with the postflight changes for subjects $A$ and $B$. By $R+4$ subject $D$ had returned to baseline and remained there through $\mathrm{R}+6$.

\section{Preflight, inflight and postflight $M$-wave summary}

The M-wave percent change as measured from the average control responses for each subject did not show a significant difference $(p>0.05)$ when tested with a global F-test (Winer 1971) as a function of test day, drop to shock delay time or test day by drop to shock delay time. These data indicate that the percent changes observed with the $\mathrm{H}$-reflex reflect the excitability of the motoneuron pool, and not local effects in the reflex arc or artifact.

\section{$M$ - and $H$-reflex recruitment curves}

The $\mathrm{M}$ and $\mathrm{H}$-reflex recruitment curves which were generated for subjects $\mathrm{A}, \mathrm{B}$ and $\mathrm{C}$ when tested with a two-way analysis of variance (Winer 1971; Lin 1983) with one repeated measure (shocks at the predetermined strengths) and one grouping factor (subjects) did not show a significant change during preflight and postflight testing, or between preflight and postflight tests. Subject D did show a significant difference between test days $(p<0.05)$, but not for tests within a specific day $(p>0.05)$. Inflight, the $\mathrm{M}$ and $\mathrm{H}$-reflex recruitment curves for subjects $A$ and $B$ were similar to those obtained during ground based testing. However, because of variability of leg position under bungie tension (confirmed by observation of video tape), the inflight $\mathrm{H}$-wave recruitment curves showed some variation. This variation was always in the form of a peak response of the H-reflex which occurred either on MET-01 or MET-06 without a consistent pattern and resulted in significant differences $(p>$ 0.01 ) as determined by points falling outside \pm 1 SEM whenever this random variation was encountered. However, all spurious points remained within \pm 2 SEM.

\section{Gastrocnemius EMG activity}

The preflight EMG data were very consistent. Latency and amplitude measurements, both within and across all four subjects indicated a stable baseline. When subjected to a two-way analysis of variance (Winer 1971) no significant differences were observed for the preflight data. Because there were no differences, a single mean score for latency and amplitude was derived. Latency of the EMG response which represented the first detectable activity following release averaged $93.97 \mathrm{~ms}$ with a variance of $\pm 5.24 \mathrm{SEM}$. The preflight mean RMS amplitude calculated over the 50 to $150 \mathrm{~ms}$ interval for each drop across all four subjects was $251 \mathrm{mv}$ and 
had a SEM of \pm 57.2 average (across all pretlight test days). Postflight EMG latency and RMS amplitude for each subject did not differ significantly $(p>0.05)$ when compared with the average preflight baseline. Postflight latency for all subjects averaged $93.63 \mathrm{~ms}$ $( \pm 4.55$ SEM), and RMS amplitude averaged 243.5 $\mathrm{mv}( \pm 59.94 \mathrm{SEM})$. Individual test day postflight for each subject, when compared with the preflight baseline did not show any significant differences. However, subject B did show an immediate postflight increase in RMS amplitude. Subject B was the first available subject and was tested approximately 130 min postflight. At that time he showed a 200\% increase in RMS amplitude when that percentage was derived as a function of the average preflight response. By 135 min postflight, the percent RMS amplitude relative to preflight had decreased to $90 \%$, and by $147 \mathrm{~min}$, return to baseline was evident.

\section{Perceived motion and sensations}

When questioned about their sensation to the sudden drop inflight, subjects $A$ and $B$ reported that on day seven (MET-06) they did not feel as though they were falling when compared to their experience on the ground, or for subject B with those drops on flight day two (MET-01). By MET-06 the sensation was described as "being shot out of a cannon" or "very abrupt and unpleasant" and "they (the drops) were a surprise when it happened". Subject B, in a postflight debriefing, said that the drops on MET-06 felt as though someone had placed their hands on his shoulders and pushed very hard causing him to be "translated" to the floor of the Spacelab. All reports were confirmed with video tapes taken of the inflight drops. It frequently appeared as though the crewmen did not know where their feet or legs were, and were unprepared to land. One subject (A) "fell" (failed to maintain his balance) several times during the MET06 drops.

The postflight drops on $\mathrm{R}+0$ and $\mathrm{R}+1$ were reported by the crewmen tested inflight to be similar to the inflight drops on MET-06. That is, the fall was hard, abrupt and the landing was a surprise. All crewmen reported that postflight the sensation was not a fall, but that the floor came up to meet their feet. These sensations continued through testing on $\mathrm{R}+2$ with a decreasing frequency.

\section{Space motion sickness and the H-reflex}

The degree and severity of space motion sickness experienced by the four crewmembers who partici- pated in this experiment was monitored as part of another experiment (Young et al. 1984; Oman et al. 1984), and in a less controlled fashion by our experiment and mission operations (Homick et al. 1984). A brief summary of the results indicated that three of the four subjects experienced frank sickness (vomiting) more than once during the first three days of the flight. The fourth crewmember was asymptomatic. When ranked (by our experiment) for severity of symptoms experienced during flight we found symptom strength to be greatest in subjects $A$ and $\mathrm{B}$, and least in subject $\mathrm{C}$. This rank order was then compared with the peak H-reflex drop to shock preflight average for each crewman and with the postflight H-reflex curves. The results show that subjects $\mathrm{A}$ and $\mathrm{B}$ (stronger symptoms) both had the greater $\mathrm{H}$-reflex potentiation preflight and postflight. Subject $\mathrm{C}$, ranked third, had less preflight H-reflex potentiation, and postflight changes quickly returned to baseline. Subject $D$, who was asymptomatic had a very low $\mathrm{H}$-reflex potentiation preflight when compared with subjects $\mathrm{A}, \mathrm{B}$ and $\mathrm{C}$, and showed only minor change postflight over his preflight $\mathrm{H}$-reflex maximum drop to shock amplitude.

A possible confounding effect on these results was the use of antisickness medication that was taken by all four crewmen. The specific details of the drug regimen have been reported by Oman et al. (1984, and in this issue). Briefly, the drug of choice was a combination of scopolamine $(0.4 \mathrm{mg})$ and dexedrine $(2.5 \mathrm{mg}$ ). This drug was used by subjects A, B and D on different schedules. Subject A took 8 doses beginning $25 \mathrm{~min}$ into the flight and stopped all medication approximately $70 \mathrm{~h}$ later. Subject B took his first of 7 doses $6 \mathrm{~h}$ into the flight and his last approximately $60 \mathrm{~h}$ later. Subject D took 6 doses on a schedule similar to that of subject B. Subject $C$ chose a combination of promethazine $(25 \mathrm{mg})$ and Ephedrine $(25 \mathrm{mg})$, and took only a single dose approximately $28 \mathrm{~h}$ into the flight.

Subjects A and B on one occasion supplemented (approximately $25 \mathrm{~h}$ into the flight) their dose of scopolamine and dexedrine with $10 \mathrm{mg}$ of metoclopramide (Reglan), and subject $\mathrm{D}$ took a Dalmane along with his scopolamine and dexedrine on the fifth hour of the flight.

Antimotion sickness drug effectiveness for the prevention of space motion sickness is currently under investigation by our laboratory. Currently, there has been no drug that has been found effective. However, the crew did report that the experience with the drugs and the drug schedule maintained on this flight may have contributed to fewer vomiting episodes and a subjective feeling that the drugs had some effect. It should be noted that subject $\mathrm{D}$ did not 
have motion sickness symptoms as a function of the flight, and only took the drugs on a prophylactic schedule. Our impression, based on experience with the flight program over the first 20 Shuttle flights, is that subject $\mathrm{D}$ would have remained asymptomatic without the medication.

\section{Discussion}

\section{Otolith reinterpretation}

We postulate that exposure to prolonged free fall produces a form of sensory-motor rearrangement, and that adaptation to this rearrangement results in reinterpretation by the brain of the otolith receptor input rather than a change in otolith receptor sensitivity. This reinterpretation is required for structured and meaningful interaction with and reaction to the altered environment of orbital flight.

Melvill Jones (1974) may have been the first to note that adaptive changes during orbital flight could leave the brain temporarily unresponsive to otolith stimulation by the steady "g" vector. Young, Oman and their colleagues (Young et al. 1984; Oman 1982) suggested "otolith reinterpretation" as one of several possible consequences of prolonged weightlessness which they examined in the MIT-Canadian Spacelab 1 experiments.

Data from this vestibulo-spinal experiment support an otolith reinterpretation hypothesis. Under normal gravity conditions, sudden free fall elicits an otolith-spinal reflex if the body's $\mathrm{Z}$ axis is parallel to the gravity vector acting on the body mass and the fall is in the direction of the gravity vector. This reflex response prepares the body for the impact deceleration of landing following the fall.

During space flight a fall, defined as linear translation parallel to gravity, is meaningless because gravity is absent. Consequently, the adaptive brain learns to interpret during flight all otolith signals as indicating linear translation rather than falls, and reflex responses ordinarily elicited by falls are lost.

Both perceptual and physiological data from this experiment support this reinterpretation hypothesis. During space flight and before adaptation, sudden unexpected drops were perceived as falls, but following adaptation the drops were perceived as sudden unexpected movement from the suspended position to the deck of the Spacelab. Crewman A reported that drops early in the flight (MET-01) felt much as they did preflight. The H-reflex changes associated with these drops also were similar to those obtained preflight. Later in the flight (MET-06) the drops were perceived as sudden, fast and hard. At least one crewman (B) described the late inflight drops as translation. The crewmen were not aware of where their legs and feet were and exhibited difficulties in maintaining balance following "landing". Late in flight the H-reflex was not potentiated by the drops.

Otolith reinterpretation was also supported by the postflight perceptual responses. The drops postflight were perceived just as they were on MET-06 inflight. That is, the crewmen were unaware of where their feet were and the drops were perceived as sudden. They did not feel as though they were falling; rather, "the floor came up to meet them".

Evidence for otolith reinterpretation was not seen in the postflight physiological response data. We suggest that the H-reflex would not have been potentiated by drops immediately after landing and that reflex readaptation had occurred prior to our first postflight observations. Apparently some reflex responses readapt to normal gravity very rapidly.

\section{The H-reflex and the direct vestibulo-spinal reflex}

We have postulated, as part of the otolith reinterpretation hypothesis, that modification of the H-reflex potentiation would reflect central and plastic changes rather than direct changes in peripheral otolith receptor sensitivity. This hypothesis may also have been supported by the results obtained from the direct vestibulo-spinal reflex recorded by Watt (Young et al. 1984), and by this experiment. We assume that changes in both the $\mathrm{H}$-reflex in response to a sudden fall and in the direct vestibulo-spinal reflex are mediated through the brain stem vestibular nuclei, and that both of these responses should have the same relative changes in magnitude and direction as a function of the flight. Inflight, this assumption was correct. That is, both the H-reflex and the direct vestibulo-spinal response (Young et al. 1984) showed a decrease in amplitude as the flight progressed. Following the flight, Watt reported (Young et al. 1984) that the direct vestibulo-spinal response was unchanged from the preflight values. Our immediate measurements of the direct vestibular-spinal reflex postflight for the first subject tested (we were to test this subject prior to his being tested by any other investigation) did show an increase in RMS amplitude which declined very rapidly to preflight values. However, neither the immediate return to baseline for the direct vestibulo-spinal reflex nor the lack of an increase in amplitude as measured by Watt (Young et al. 1984) was consistent with the large postflight potentiation of the H-reflex.

The large potentiation of the $\mathrm{H}$-reflex postflight has been supported by the results from several Soviet flights which found similar postflight changes in both the $\mathrm{H}$ and T-reflexes for 8 out of 10 crewmembers 
(Kozlovskaya et al. 1981, 1982, 1983). A potentiation of the T-reflex was also observed following one of our Skylab flights (Baker et al. 1977). It is important to note that the Soviets report recovery curves that were not complete even by the seventh day postflight. While these observations support our results, and the flight related changes in the sensory motor control system are clearly evident, the precise mechanisms underlying these changes are not currently understood.

\section{Ground vs. flight drops}

There were several differences between the drop stimulus encountered by the astronauts during preflight and postflight testing and those experienced during orbital flight. First, the ground based drops provided a step acceleration from $1 \mathrm{~g}$ to $0 \mathrm{~g}$. Inflight the stimulus provided a negative acceleration from $0 \mathrm{~g}$ to $-1 \mathrm{~g}$ when the calibrated bungie cords pulled the subjects to the deck of the Spacelab. The inflight drops were not a constant step acceleration. That is, the bungie cords were linear only over a small range and would quickly "unload". Second, the position of the otoconia in sustained free fall provided a neural bias that would be different than that encountered during ground testing. This would be particularly true if the primary otolith organs stimulated by a sudden fall were saccular.

There is some support for a change in saccular bias. Gualtierotti (1972) reported (the only otolith organ single unit data obtained from orbital flight) that frog utriculo-saccular receptor units show a slow cyclic modulation following introduction into weightlessness, and that after 4 to 5 days unit response rate is analogous to that observed preflight. Superimposed on the adapted state was an increased sensitivity to transient acceleration.

However, neither our $\mathrm{H}$-wave recruitment data, nor our inflight drop data confirm the existence of a change in saccular bias. That is, the inflight recruitment data for subject A (the only subject from which recruitment data was obtained early and late inflight) indicated no change in either percent change or threshold of the H-reflex. The drops for subject $\mathrm{A}$ indicated on MET-01 H-reflex percent changes similar to those obtained preflight, while the responses on MET-06 were not potentiated as a function of the drop to shock delays.

\section{Experimental control parameters}

What influence do stimuli other than descending vestibular signals have on the lumbosacral moto- neuron pool, and can their influence affect the $\mathrm{H}$ reflex response recorded during a sudden fall? Stretch, either active or passive, of the soleus or anterior tibial muscle (Hoehler et al. 1981; Taborikova et al. 1966; Hugon 1973; Tanaka 1976; Buchthal and Schmalbruch 1976; Gottlieb and Agarwal 1978) can affect the amplitude of the H-reflex. However, modulation of the H-reflex typically has a latency between 100 and $400 \mathrm{~ms}$ following muscle stretch (Taborikova 1966), and a latency as long as $300 \mathrm{~ms}$ following a voluntary plantarflexion of the foot (Gottlieb and Agarwal 1978). These long latencies made it unlikely that either the voluntary or involuntary foot movement would affect the amplitude of the H-reflex during this experiment. For control purposes (Reschke et al. 1984b), position of the foot and rotation of the ankle were observed with both the recorded EMG from the Gastrocnemius and of foot angle from film or videotape obtained during the fall. Data obtained from these measurements indicated that rotation of the ankle (dorsiflexion) did not begin until well into the drop (> $80 \mathrm{~ms}$ ).

Segmental influence produced by muscle activity in addition to that found in the soleus/gastrocnemius complex was also a concern. Specifically, there was concern that if the subject was required to hold his body weight with his hands and arms prior to a drop, the cervical input could make the H-reflex response inconsistent and variable, or produce a potentiation such as that seen when a Jendrassik maneuver is performed (Gassel and Diamantopoulos 1964). The special harness which we used for the drops did not require the astronaut to bear his weight with arms and hands. Hands were only placed on the drop mechanism to stabilize the body, or in the case of the $0 \mathrm{~g}$ drops to prevent the drop handle from striking the subject's head.

Proprioceptive and cutaneous input can also modulate the H-reflex (Táboříková 1973) through inhibition. This is particularly true if the proprioceptive or cutaneous input shares the same dermatome with the lumbosacral motoneuron pool. To prevent this type of interaction, care was taken to insure that straps or any moving part of the drop apparatus did not come in contact with the legs or feet. In addition, electrical current strengths were always kept at a minimum level to reduce cutaneous input.

\section{H-reflex and space motion sickness}

An interesting finding of this investigation was the relationship of space motion sickness to amplitude of the H-reflex. There are three possible explanations 
for this observation. First, the amplitude of the Hreflex could be related to the relative weight each individual crewman assigns to the utriculo-saccular system for spatial orientation. It is now clear that head movement in orbital flight is associated with space sickness (Young et al. 1984; Thornton 1983; Parker et al. 1985), and that pitch and roll head movements are particularly provocative. Those individuals who do not rely heavily on information from the otolith receptors to provide spatial orientation may find head movements in weightlessness to be less of a problem (less provocative and less disturbing). That is, they may easily reinterpret the signals from the utriculo-saccular system and on this basis modify responses (including eye movements, vestibulo-spinal signals and other physiological parameters) to be consistent with their self-motion perception.

Second, the rate at which signals are reinterpreted may also be an important feature in the adaptation process. The one crewman who was asymptomatic on the Spacelab-1 flight, and the second who had less severe symptoms, were the two crewmembers who also showed the most rapid return to their preflight $\mathrm{H}$-reflex baseline following the flight. They were able to reinterpret the otolith signal more rapidly than those who were ill for a longer period of time.

The third possibility would include both of the above alternatives. That is, the ideal protection against space motion sickness would be to assign less weight to the otolith receptor input, and to modify the remaining input as rapidly as possible. Some support for this hypothesis was obtained with one crewperson who flew recently, and from whom we were able to obtain preflight and postflight H-reflex responses to a sudden drop (Reschke 1985b). This astronaut's preflight H-reflex drop to shock potentiation curve was very similar to subject A's on the Spacelab 1 flight. From this curve we predicted that this crewperson would experience space motion sickness. This prediction was confirmed. The postflight test did not show a large potentiation, and from this data we further predicted that his motion sickness episode inflight would be limited. This prediction was also confirmed.

Acknowledgements. Every experiment that is space flight related owes its success to many individuals, without whom the major objectives of that research would not be accomplished. Although it is not possible to mention all those concerned, we are particularly pleased to acknowledge Scott Wood for his dedicated effort, Dr. Hatamian for his work with the flight hardware, Dr. Karl Lin for his assistance with the statistical analysis, Drs. Makoto Igarashi and D.E. Parker for their recommendations, Ms. Carol Verrett for the many editions of this manuscript which she typed, and Joe Baker as our experiment manager. We would also like to acknowledge the following: R. Clark, W. Crosier, K. Elton, J. Evans, M. Flores, L. Forrest, R. Gibson, P. Grounds, K. Holmes, K. Jones, B. Kitchen, C. Litton, F. Looft, E. Peck, P. Ryan, G. Salinas, and T. Watson. We would particularly like to thank the Spacelab-1 crew who helped make this research possible, and those responsible for the Baseline Data Collection Facilities at NASA-Dryden and the Kennedy Space Center.

\section{References}

Baker JT, Nicogassian AE, Hoffler GW, Johnson RL, Hordinsky $J$ (1977) Measurement of a single tendon reflex in conjunction with myogram: the second manned skylab mission. In: Biomedical results from skylab. NASA SP-377: p 131

Buchthal F, Schmalbruch H (1976) Contraction times of reflexly activated motor units and excitability cycle of the H-reflex. In: Homma S (ed) Understanding the stretch reflex. Prog Brain Res 44: 367-375

Clement G, Gurfinkel VS, Lestienne F (1985) Mechanisms of posture maintenance in weightlessness. Vestibular and visual control on posture and locomotor equilibrium. Igarashi and Black (eds), pp 158-163

Dunnett CW (1964) New tables for multiple comparisons with a control. Biometrics 20: 482-491

Gassel MM, Diamantopoulos E (1964) Pattern of conduction times in the distribution of the radial nerve. Neurology (Minneap) 14: 222-231

Gottlieb GL, Agarwal GC (1978) Stretch and Hoffmann reflexes during phasic voluntary contractions of the human soleus muscle. Electroenceph Clin Neurol 44: 553-561

Greenhouse SW, Geiser S (1959) On methods in the analysis of profile data. Psychometrika 24: 95-112

Greenwood RJ, Hopkins AP (1974) Muscle activity in falling man. J Physiol (Lond) 241: 26-27

Greenwood RJ, Hopkins AP (1976a) Landing from an unexpected fall and a volunteer step. Brain 99: 375-386

Greenwood RJ, Hopkins AP (1976b) Muscle responses during sudden falls in man. J Physiol (Lond) 254: 507-518

Greenwood RJ, Hopkins AP (1977) Monosynaptic reflexes in falling man. Neurol Neurosurg Psychiat 40: 448-454

Gualtierotti T (1972) Orbiting frog otolith experiment: (OFO$A O)$. Final report on the data reduction and central experimentation, NASA-Contract NASW-2211. Piccin Medical Books: prepared by University of Milan

Hoehler FK, McCann MA, Bernick DL (1981) Habituation of the Hoffmann reflex. Brain Res 220: 299-307

Hoffmann P (1918) Über die Beziehungen der Sehnenreflexe zur willkürlichen Bewegung und zum Tonus. Z Biol 68: 351-356

Hoffmann P (1922) Untersuchungen über die Eigenreflexe (Sehnenreflexe) menschlicher Muskeln. Springer, Berlin

Homick JL, Reschke MF (1977) Postural equilibrium following exposure to weightless space flight. Acta Oto-Laryngol 83: 455-464

Homick JL, Reschke MF, Vanderploeg JM (1984) Space adapta* tion syndrome: incidence and operational implications for the space transportation system program. In: Motion sickness: mechanisms, prediction, prevention and treatment. North Atlantic Treaty Organization, Neuilly-sur-Seine, France, pp36.1-36.6

Hugon M (1973) Methodology of the Hoffman reflex in man. In: Desmedt JE (ed) New development in electromyography and chemical neurophysiology, Vol 3, pp 277-293

Kozlovskaya IB, Kreidich YuV, Rakham OV (1981) Mechanisms of the effects of weightlessness on the motor system of man. Physiologist Suppl 24: 59-64 
Kozlovskaya IB, Aslanova IF, Grigorieva LS, Kreidich YuV (1982) Experimental analysis of motor effects of weightlessness. Physiologist Suppl 25: 49-52

Kozlovskaya IB, Aslanova IF, Barmin VA, Grigorieva LS, Gevlich GI, Kirenskaya AV, Sirota MG (1983) The nature and characteristics of a gravitational ataxia. Physiologist Suppl 26: 108-109

Lackner JR (1978) Some mechanisms underlying sensory and postural stability in man. In: Held R, Leibowitz $\mathrm{HW}$, Teuber HL (eds) Handbook of sensory physiology, Vol 3, pp 806-845

Lin KK (1983) Statistical models for 4-factor experiments with repeated measures. A technical report, Life Sciences Division, Technology Incorporated, Houston, Texas

Magladery JW (1955) Some observations on spinal reflexes in man. Pflügers Arch Ges Physiol 261: 302-321

Matthews Sir Bryan, Whiteside TCD (1960) Tendon reflexes in free fall. Proc R Soc B 153: 195-204

Melvill Jones G, Watt DGD (1971) Muscular control of landing from unexpected falls in man. J Physiol 219: 729-737

Melvill Jones G (1974) Adaptive neurobiology in space flight. The Proceedings of the Skylab Life Science Symposium, Vol 2, NASA TM X-58154. Houston: National Aeronautics and Space Administration, pp 847-860

Oman CM (1982) Space motion sickness and the vestibular experiments in Skylab. Twelfth Intersociety Conference on Environmental Systems, Society of Automotive Engineers, San Diego

Oman CM, Lichtenberg BK, Money KE (1984) Space motion sickness monitoring experiment: spacelab 1. In: Motion sickness: mechanisms, prediction, prevention and treatment. North Atlantic Treaty Organization, Neuilly-sur-Seine, France, pp 35.1-35.21

Parker DE, Reschke MF, Arrott AP, Homick JL, Lichtenberg BK (1984) Preliminary DSO 0433 Summary Report for STS11(41-B). National Aeronautics and Space Administration, Houston

Parker DE, Reschke MF, Arrott AP, Homick JL, Lichtenberg BK (1983) DSO 0433 Summary Report for STS-8. National Acronautics and Space Administration, Houston

Parker DE, Reschke MF, Arrott AP, Homick JL, Lichtenberg BK (1985) Otolith tilt-translation reinterpretation following prolonged weightlessness: implications for preflight training. Aviat Space Env Med 56: 601-606

Reschke MF, Anderson DJ, Homick JL (1984a) Vestibulospinal reflexes as a function of microgravity. Science 225: 212-213

Reschke MF, Parker DE, Homick JL, Anderson DJ, Arrott AP, Lichtenberg BK (1984b) Reinterpretation of otolith input as a primary factor in space motion sickness. In: NATO/AGARD Aerospace Medical Panel Symposium: Results of Space Experiments in Physiology and Medicine. Istanbul, Turkey, pp 3-1 to 3-18

Reschke MF (1985b) Unpublished data from Spacelab-3

Reschke MF, Anderson DJ, Moore M, Homick JL (1976) Vestibulo-spinal responses as a function of zero-g. Soc Neurosci Abstr 2: 1061

Reschke MF, Homick JL, Anderson DJ (1985a) Development of vestibulospinal reflex measurements as a method for the investigation of statotolith function during sustained weightlessness. Vestibular and visual control on posture and locomotor equilibrium. Igarashi and Black (eds), pp 151-157

Reschke MF, Homick JL, Baker JT (1979) Vestibulo-spinal reflexes in man as a function of linear acceleration. Aerospace Med Assoc Abstr, pp 298-299

Táboříková H (1973) Supraspinal influences on H-reflexes. In: Desmedt JE (ed) New development in electromyography and clinical neurophysiology, Vol 3, pp 328-336

Táboříková H, Provini L, Decandia M (1966) Evidence that muscle stretch evokes long-loop reflexes from higher centers. Brain Res 2: 188-192

Tanaka R (1976) Reciprocal Ia inhibition and voluntary movements in man. Understanding the stretch reflex. Homma $S$ (ed). Prog Brain Res 44: 291-301

Thornton WE (1983) Report of STS-8 Biomedical DSO Results. Presentation to USRA Space Adaptation Working Panel. Unpublished data. Johnson Space Center, Houston, Texas

Vorokyov Yel, Gazenko OG, Genin AM, Egorov AD (1982) Basic medical results of the latest USSR space flights. Thirtythird Congress of the International Astronautical Federation, pp 2-5

Watt DGD (1976) Responses of cats to sudden falls: an otolithoriginating reflex assisting landing. J Neurophysiol 39: 257-264

Watt DGD (1981) Effect of vertical linear acceleration on H-reflex in decerebrate cat I.Transient stimuli. J Neurophysiol 45: 644-655

Winer BJ (1971) Statistical principles in experimental designs, 2nd edn. McGraw-Hill, New York, pp 201-204, 539-559

Young LR, Oman CM, Watt DGD, Money KE, Lichtenberg BK (1984) Spatial orientation in weightlessness and readaptation to earth's gravity. Science 225: 205-208

Received August 8, 1985 / Accepted July 1, 1986 